\title{
MATERNAL AND PERINATAL OUTCOME IN PATIENTS WITH SEVERE PRE ECLAMPSIA/ ECLAMPSIA WITH AND WITHOUT HELLP SYNDROME.
}

\author{
Gupta T. ${ }^{1}$, Gupta N.', Jain J., Gupta S. ${ }^{2}$, Bhatia P., Bagla J. ${ }^{5}$
}

\begin{abstract}
OBJECTIVE: To evaluate the occurrence of HELLP syndrome in patients with severe pre eclampsia \& eclampsia and to compare the maternal \& perinatal outcome in patients with and without HELLP syndrome (partial and true).

METHOD: This was a prospective longitudinal study conducted in the Department of Obstetrics \& Gynaecology, E.S.I. PGIMSR,NewDelhi from August 2011-April 2013. 50 pregnant women with singleton pregnancy with severe pre eclampsia detected at 28 or more weeks of gestation were enrolled. Patients were divided into three groups: group 1 with severe pre eclampsia, group 2 with severe pre eclampsia with partial HELLP syndrome and group 3 with severe pre eclampsia with true HELLP syndrome. Patients in three groups were compared in regard to maternal complications, gestational age at delivery, mode of delivery, hospital stay and perinatal outcome.
\end{abstract}

RESULTS: Prevalence of HELLP syndrome in severe pre eclampsia was 40\% (partial HELLP=28\% and true=12\%). Antenatal and maternal complications were more in true HELLP syndrome patients as compared to other groups. PPH was observed in $40 \%$ of entire study group. DIC was found more in true HELLP syndrome patient with high statistically significant $\mathrm{p}$ value $<0.001$ Blood and its product transfusion was more in true HELLP syndrome. There was $100 \%$ ICU admission in group 3. In severe pre eclampsia, 11 neonates had birth weight $>2.5 \mathrm{~kg}$. Where as in partial and true HELLP syndrome, no neonate had birth weight more than $2.5 \mathrm{~kg}$. This difference was statistically significant. There was $100 \%$ NICU admission in HELLP syndrome, $91.66 \%$ in partial HELLP syndrome and $42.3 \%$ in severe preeclampsia. The perinatal morbidity and mortality was higher in HELLP syndrome patients than in patient with severe pre eclampsia without HELLP syndrome.

CONCLUSION: The study concludes that both maternal and perinatal outcome were adverse in HELLP syndrome than in severe pre eclampsia without HELLP syndrome.

KEYWORDS: HELLP syndrome, Severe pre eclampsia, Maternal mortality

1. Associate Professor, Department of Obstetrics and Gynaecology, ESI Postgraduate Institute of Medical Sciences \& Research, Delhi, India

2. Assistant Professor, Department of Obstetrics and Gynaecology, ESI Postgraduate Institute of Medical Sciences \& Research, Delhi, India

3. Post Graduate Resident, Department of Obstetrics and Gynaecology, ESI Postgraduate Institute of Medical Sciences \& Research, Delhi, India

4. Professor, Department of Obstetrics and Gynaecology, ESI Postgraduate Institute of Medical Sciences \& Research, Delhi, India

5. Associate Professor, Department of Paediatrics, ESI Postgraduate Institute of Medical Sciences \& Research, Delhi, India

\author{
For correspondence \\ Dr. Taru Gupta, \\ Associate Professor, \\ Department of Obstetrics and Gynaecology, \\ ESI Postgraduate Institute of Medical Sciences \& Research, \\ Delhi, India \\ E-mail: tarugupta1971@yahoo.com
}




\section{INTRODUCTION}

Hypertensive disorders during pregnancy represent a significant public health problem throughout the world. The global incidence of pre eclampsia has been estimated at 5-14\% of all pregnancies. In developing nations, incidence of pre eclampsia is reported to be $4-18 \%$, with hypertensive disorders being second most common obstetric cause of stillbirth and early neonatal deaths in this countries. ${ }^{2}$ Pre eclampsia is mild in $75 \%$ of cases and severe in $25 \%$ of them. ${ }^{3}$

Pre eclampsia is best described as a pregnancy specific syndrome of reduced organ perfusion secondary to vasospasm and endothelial activation. Proteinuria is an important sign of pre eclampsia. Minimal criteria for diagnosis is BP $\geq 140 / 90$ $\mathrm{mmHg}$ after 20 weeks gestation and Proteinuria $\geq 300 \mathrm{mg} / 24 \mathrm{hrs}$ or $\geq 1+$ dipstick. It can be classified as mild or severe pre eclampsia; cut off used to define severe pre eclampsia are $\mathrm{BP} \geq 160 / 110$ with Proteinuria persistently $2+$ or more. In severe pre eclampsia patient may present with headache, visual disturbance, upper abdominal pain or oliguria. The onset of convulsions in a woman with pre eclampsia that cannot be attributed to other causes is termed as eclampsia.

HELLP syndrome develops in 1 of 1000 pregnancies overall ${ }^{4} \&$ in $4-12 \%$ of patients already affected by severe pre eclampsia or eclampsia. ${ }^{5}$ The acronym HELLP was coined by Weinsten in 1982 to describe a syndrome consisting of Hemolysis, Elevated liver enzyme levels and low platelet count. According to Tennessee classification HELLP syndrome is divided into true / complete and partial / incomplete HELLP syndrome; true HELLP if all three criteria i.e. Hemolysis, Elevated Liver Enzyme and low platelet count are present and partial if severe eclampsia with anyone of the following: ELLP, HEL, EL, LP ${ }^{7}$ are present. Women with partial HELLP syndrome (PHS) should be managed separately from women with true HELLP syndrome or severe pre eclampsia.

The incidence of true HELLP syndrome is 2 to $12 \%$, while the incidence of PHS is unclear, but probably around 21 to $24 \%^{8-9}$ in severe pre eclampsia. Clinical and laboratory parameters in HELLP syndrome are predictive of adverse maternal outcome. ${ }^{10}$ Furthermore, HELLP syndrome is associated with increased risk of poor fetal outcome, as it results in intrauterine fetal growth restriction, intrauterine fetal death and prematurity, and an elevated perinatal mortality rate. ${ }^{11}$

\section{METHODOLOGY}

This prospective longitudinal study was conducted in the Department of Obstetrics \& Gynecology, E.S.I. PGIMSR, New Delhi from August 2011 to April 2013. 50 pregnant females with severe pre eclampsia or eclampsia detected at 28 or more weeks of gestation were enrolled in the study. Patients with known case of renal and liver disorders, diabetes mellitus $\&$ heart disease, multiple pregnancy, gestational hypertension, chronic hypertension and with any cause of convulsions other than eclampsia were excluded from the study.

50 patients were divided in three groups: group 1with severe pre eclampsia, group 2 with severe pre eclampsia with partial HELLP syndrome and group 3 with severe pre eclampsia with true HELLP syndrome.

At recruitment informed consent was taken in all the cases. Each patient was subjected to a detailed history and thorough clinical examination. Gestational age was determined using Naegle's formula and confirmed with ultrasound. Cut offs used to define severe pre eclampsia were BP $\geq 160 / 110 \mathrm{mmhg}$ or higher and proteinuria persistently $2+$ or more.HELLP syndrome was defined by presence of all three criteria: Hemolysis (characteristic peripheral blood smear, serum LDH $\geq 600 \mathrm{u} / \mathrm{L}$, total serum bilirubin $\geq 1.2 \mathrm{mg} / \mathrm{ml}$ ), increased liver enzyme (serum aspartate aminotransferase $\geq 70 \mathrm{U} / 1$ \& serum alanine aminotranferase $\geq 70 \mathrm{u} / 1)$ \& low platelet $(\leq 1$, $50,000 / \mathrm{ul})$. Partial HELLP syndrome defined by severe pre eclampsia with anyone of the following: ELLP (elevated liver enzymes with low platelet count), HEL (hemolysis with elevated liver enzymes), EL (elevated liver enzymes), LP (low platelet count) according to Tennessee classification.

On admission, brief history was taken and examination including GPE and local examination was done. Hematocrite, platelet count, liver enzymes and urine routine microscopy was determined and $24 \mathrm{hrs}$ urine collection was done for total protein. Hemogram and blood biochemistry tests were repeated daily or earlier if required. After assessment and stabilization of maternal status, the fetus was evaluated by FHR tracing, biophysical profile and / or doppler if required.

Labetolol / alpha methyldopa was used as antihypertensive agents. $\mathrm{MgsO}_{4}$ regimewas started as per the Pritchard regimen in patient with persistently increased systolic or diastolic blood pressure and /or prodromal symptoms of eclampsia. 2 doses of betamethasone (12mg i.m) at $24 \mathrm{hr}$ interval was given if patients gestational age $<34 \mathrm{wks}$. The definitive treatment of severe pre eclampsia and HELLP syndrome is termination of pregnancy.

Patients in three groups were compared in regard to maternal complications (imminent eclampsia, eclampsia, abruption placenta, pulmonary edema, acute renal disease and maternal mortality), gestational age at delivery, mode of delivery, oligohydroamnios and time of hospital stay and perinatal outcome in terms of apgar score at $1 \& 5 \mathrm{~min}$, birth weight, perinatal morbidity and mortality if any. 


\section{RESULTS}

Prevalence of HELLP syndrome in severe pre eclampsia was $40 \%$ with prevalence of partial HELLP syndrome $28 \%$ and true HELLP syndrome $12 \%$. Mean age was $26.17 \pm 3.95 \mathrm{yrs}$ in group $1,24.57 \pm 3.96 \mathrm{yrs}$ in group 2 and $29.50 \pm 2.51 \mathrm{yrs}$ in group 3. The study concluded that mean age was higher in HELLP syndrome. The majority of patients in our study were primigravida (34\%). Most of the patients were unbooked and referred cases. 50\% patients with HELLP syndrome were unbooked.

In group 1, out of 30 patients nine had caesarean and 21 had normal vaginal delivery. Out of these 21 patients, 13 were in spontaneous labour and 8 were induced. In group 1 , there were two assisted vaginal delivery. In group 2, out of 14 patients seven had vaginal delivery and seven had caesarean. Out of these seven vaginal delivery, 4 went in spontaneous labour and rest three were induced. In Group 3, four had vaginal delivery, out of which 3 were induced and two had caesarean, one for previous 2 LSCS and another for fetal distress. Platelet count was low in true HELLP syndrome. Mean value of platelet count in group 1 was $2.19 \pm 0.39$; in group 2 was $1.32 \pm 0.45$ and $0.99 \pm 0.19$ in Group 3. There was significant decrease in platelet count in patients with (true and partial) HELLP syndrome. This difference was statistically significant. Mean value of LDH (indicator of hemolysis) was $880 \pm 163.79$, found significantly high in true HELLP syndrome in comparison with partial HELLP syndrome and severe pre eclampsia.

Antenatal complications (Table 1) were more in HELLP syndrome patients as compared to other groups. The oligohydroamnios, preterm, PROM, IUGR and IUD were more in HELLP patients, though not statistically significant.
Overall maternal complications were found more in HELLP syndrome.

Major maternal complications were presented in Table 2. PPH was observed in $40 \%$ of study group. DIC was found more in HELLP syndrome patient than other two groups with high statistically significant $p$ value $<0.001$. Blood and its product transfusion was more in HELLP syndrome. There was $100 \%$ ICU admission in HELLP syndrome patients. So, patients with HELLP syndrome should ideally be managed in tertiary care facility. Mean days of hospital stay was $11.67 \pm 6.50$ in HELLP syndrome, $10.93 \pm 3.43$ days in partial HELLP syndrome and $7.77 \pm 3.36$ days in severe pre eclampsia. This difference was statistically significant. There were 2 maternal deaths in true HELLP syndrome patient and one in severe pre eclampsia. Patient in group 1 had post partum eclampsia and died due to acute renal failure with pulmonary oedema. In group 3 (true HELLP syndrome), two patients died due to severe abruptio placentae with acute renal failure.

In severe pre eclampsia, $42.3 \%$ neonates had birth weight $>2.5 \mathrm{~kg}$. Whereas in partial and true HELLP syndrome, no neonate had birth weight more than $2.5 \mathrm{~kg}$. This difference was statistically significant. There was $100 \%$ NICU admission in HELLP syndrome, $91.66 \%$ in partial HELLP syndrome and $42.3 \%$ in severe pre eclampsia (table 3 ).

The perinatal morbidity and mortality was higher in HELLP syndrome patients than in patient with severe pre eclampsia without HELLP syndrome. Hence the present study concluded that both maternal and perinatal outcome were adverse in HELLP syndrome than in severe pre eclampsia without HELLP syndrome (Table 4).

Table 1: Comparison of ANC complication between the groups

\begin{tabular}{|c|c|c|c|c|c|c|c|}
\hline \multirow[t]{2}{*}{ ANC Complication } & \multirow{2}{*}{$\begin{array}{c}\text { Group } 1 \\
(30)\end{array}$} & \multirow{2}{*}{$\begin{array}{c}\text { Group } 2 \\
\text { (14) }\end{array}$} & \multirow{2}{*}{$\begin{array}{c}\text { Group } 3 \\
\text { (6) }\end{array}$} & \multicolumn{4}{|c|}{ p Value } \\
\hline & & & & overall & Group1 vs 2 & Group1 vs 3 & Group 2 vs 3 \\
\hline Oligo & $26.7 \%$ & $42.9 \%$ & $16.7 \%$ & 0.413 & 0.283 & 1.000 & 0.354 \\
\hline Preterm labor & $13.3 \%$ & $35.7 \%$ & $50 \%$ & 0.076 & 0.117 & 0.073 & 0.642 \\
\hline PROM & $10 \%$ & $14.3 \%$ & $0 \%$ & 0.621 & 0.647 & 1.000 & 1.000 \\
\hline IUGR & $3.3 \%$ & $42.9 \%$ & $33.3 \%$ & 0.004 & 0.002 & 0.066 & 1.000 \\
\hline IUD & $13.3 \%$ & $14.3 \%$ & $50 \%$ & 0.090 & 1.000 & 0.073 & 0.131 \\
\hline
\end{tabular}


Gupta T., Gupta N., Jain J., Gupta S., Bhatia P., Bagla J.

Table 2: Comparison of maternal complications

\begin{tabular}{|c|c|c|c|c|c|c|c|}
\hline \multirow[t]{2}{*}{ Maternal complication } & \multirow{2}{*}{$\begin{array}{c}\text { Group } 1 \\
\text { (30) }\end{array}$} & \multirow{2}{*}{$\begin{array}{c}\text { Group } 2 \\
\text { (14) }\end{array}$} & \multirow{2}{*}{$\begin{array}{c}\text { Group } 3 \\
\text { (6) }\end{array}$} & \multicolumn{4}{|c|}{ p value } \\
\hline & & & & overall & Group 1 vs 2 & Group 1 vs 3 & Group 2 vs 3 \\
\hline Abruptio Placentae & $3.3 \%$ & $7.1 \%$ & $66.7 \%$ & $<0.001$ & 0.540 & 0.001 & 0.014 \\
\hline PPH & $23.3 \%$ & $71.4 \%$ & $50 \%$ & 0.009 & 0.006 & 0.317 & 0.613 \\
\hline DIC & $0 \%$ & $14.3 \%$ & $83.3 \%$ & $<0.001$ & 0.096 & $<0.001$ & 0.007 \\
\hline $\mathrm{ARF}$ & $0 \%$ & $7.1 \%$ & $50 \%$ & $<0.001$ & 0.318 & 0.003 & 0.061 \\
\hline PE & $6.7 \%$ & $28.6 \%$ & $50 \%$ & 0.020 & 0.071 & 0.024 & 0.613 \\
\hline ARDS & $3.3 \%$ & $0 \%$ & $16.7 \%$ & 0.210 & 1.000 & 0.310 & 0.300 \\
\hline ND & $0 \%$ & $0 \%$ & $0 \%$ & - & - & - & - \\
\hline $\mathrm{VC}$ & $10 \%$ & $14.3 \%$ & $0 \%$ & 0.621 & 0.647 & 1.000 & 1.000 \\
\hline $\mathrm{ICH}$ & $0 \%$ & $0 \%$ & $0 \%$ & - & - & - & - \\
\hline
\end{tabular}

PE : Pulmonary Oedema

ND : Neurological Deficit

$\mathrm{VC}$ : Visual Changes

$\mathrm{ICH}:$ Intracranial Haemorrhage

Table 3: Birth weights of neonates

\begin{tabular}{|c|c|c|c|c|c|c|c|}
\hline \multirow{2}{*}{$\begin{array}{l}\text { Birth } \\
\text { weight(kg) }\end{array}$} & \multirow{2}{*}{$\begin{array}{c}\text { Group } 1 \\
(30)\end{array}$} & \multirow{2}{*}{$\begin{array}{c}\text { Group } 2 \\
\text { (14) }\end{array}$} & \multirow{2}{*}{$\begin{array}{c}\text { Group } 3 \\
\text { (6) }\end{array}$} & \multicolumn{4}{|c|}{ p Value } \\
\hline & & & & overall & Group 1 vs 2 & Group 1 vs 3 & Group 2 vs 3 \\
\hline$<1.5$ & $16.7 \%$ & $57.1 \%$ & $83.3 \%$ & \multirow{4}{*}{0.007} & \multirow{4}{*}{0.012} & \multirow{4}{*}{0.008} & \multirow{4}{*}{0.463} \\
\hline $1.5-2$ & $23.3 \%$ & $28.6 \%$ & $16.7 \%$ & & & & \\
\hline $2.1-2.5$ & $23.3 \%$ & $14.3 \%$ & $0 \%$ & & & & \\
\hline$>2.5$ & $42.3 \%$ & $0 \%$ & $0 \%$ & & & & \\
\hline
\end{tabular}

Table 4: Comparison of neonatal morbidity between groups

\begin{tabular}{|l|l|l|l|l|l|l|l|}
\hline Neonatal complications & \multirow{2}{*}{$\begin{array}{c}\text { Group 1 } \\
\text { (26) }\end{array}$} & Group 2 & Group 3 & \multicolumn{5}{|c|}{ p value } \\
\cline { 5 - 9 } & & $\mathbf{1 2})$ & $\mathbf{( 3 )}$ & overall & Group 1 vs 2 & Group 1 vs 3 & Group 2 vs 3 \\
\hline RDS & $34.6 \%$ & $75 \%$ & $66.7 \%$ & 0.046 & 0.035 & 0.539 & 1.000 \\
\hline Sepsis & $7.7 \%$ & $0 \%$ & $33.3 \%$ & 0.139 & 1.000 & 0.288 & 0.200 \\
\hline Neonatal jaundice & $3.8 \%$ & $50 \%$ & $66.7 \%$ & 0.001 & 0.002 & 0.022 & 1.000 \\
\hline Hypoglycemia & $0 \%$ & $8.3 \%$ & $33.3 \%$ & 0.058 & 0.316 & 0.103 & 0.371 \\
\hline Shock & $7.7 \%$ & $0 \%$ & $33.3 \%$ & 0.139 & 1.000 & 0.288 & 0.200 \\
\hline
\end{tabular}




\section{DISCUSSION}

Hypertensive disorders of pregnancy represent a significant public health problem throughout the world, and preeclampsia is most common of these disorders. It complicate $5-10 \%$ of all pregnancies and are a primary cause of maternal and neonatal morbidity and mortality. ${ }^{12,13}$ HELLP syndrome develops in 1 in 1000 pregnancies overall $^{8}$ and in $4-12 \%$ of patients already affected by severe preeclampsia and eclampsia. The mortality rate of women with HELLP syndrome is approximately $1.1 \%{ }^{14}$ From 1 to $25 \%$ of affected female develops serious complications such as DIC, Placental Abruption, Adult Respiratory Distress Syndrome, Hepatorenal failure, Pulmonary Edema, Sub capsular hematoma and Hepatic rupture. A significant percentage of patients receive blood products. ${ }^{14}$

Infant morbidity and mortality rates range from $10-16 \%$, depending on the severity of maternal disease. Infant of mothers with HELLP syndrome are more likely to experience intrauterine growth retardation and respiratory distress syndrome. $^{15}$ There is $19-27 \%$ risk of developing HELLP syndrome in subsequent pregnancies. They also have up to $43 \%$ risk of developing preeclampsia in another pregnancy. ${ }^{16}$ Kumru et al (2005) compared maternal and perinatal outcome in patients with HELLP syndrome and severe preeclampsia through retrospective analysis. It was found that HELLP syndrome had a higher liver transaminase and lactic dehydrogenase levels. In addition, HELLP syndrome had more transfusion of blood, platelets and cryoprecipitate than those of other group. HELLP syndrome had significantly higher IUD. Moreover, NICU admission and neonatal mortalities were higher in HELLP syndrome than other group but that was not statistically significant. They concluded that HELLP syndrome had increased transfusion requirement and increased perinatal mortality and morbidity ${ }^{17}$.

In a retrospective study by Liu et al (2006), concluded that MODS (Multiple Organ Dysfunction Syndrome) was the strongest morbidity factor associated with patients of complete HELLP syndrome $(100 \%)$, partial HELLP syndrome (56.5\%) \& severe preeclampsia (24.3\%). Similarly, DIC (Disseminated Intravascular coagulation) was the significant outcome variable and was $50 \%, 25 \%$, \& $0 \%$ in the three groups respectively. Apgar score less than 5 at 1 minute and DIC remained significantly associated with HELLP syndrome. $^{18}$

Yildirim et al (2011) conducted a prospective study to compare maternal and perinatal complicated by severe preeclampsia, eclampsia and HELLP syndrome They concluded that overall incidence of adverse maternal outcome was $5.9 \%$ in hypertensive disorder. The rates of adverse maternal outcome for women with HELLP syndrome and eclampsia were higher than for severe preeclampsia. Birth weight was lower in patients with HELLP syndrome than in patients with severe preeclampsia and eclampsia. No significant difference in neonatal morbidity was found among three groups. Perinatal mortality tended to be higher in severe preeclampsia group than in HELLP syndrome and eclampsia group. Perinatal and neonatal outcomes in pregnancies complicated by severe preeclampsia, eclampsia, and HELLP syndrome were dependent on gestational age rather than being disease dependent. ${ }^{19}$

\section{CONCLUSION}

From the study it was concluded that HELLP syndrome is a serious complication of severe preeclampsia associated with increased maternal and perinatal morbidity and mortality. Most of the patient with HELLP syndrome requires intensive care unit for both maternal and neonatal care. These patients require more blood and blood product transfusion. So, these patients should be managed in tertiary care centre.

\section{REFRENCES}

1. Khedun SM, Moodley J, Naicker T, Maharaj B. Drug management of hypertensive disorders of pregnancy. Pharmacol Ther.1997; 74(2):221-58.

2. Ngoc NT, Merialdi M, Abdel-Aleem H, Carroli G, Purwar M, Zavaleta $N$, et al. Causes of stillbirths and early neonatal deaths: data from 7993 pregnancies in six developing countries. Bull World Health Organ 2006: 84(9):699-705.

3. Sibai BM. Magnesium sulfate prophylaxis in preeclampsia: lessons learnt from recent trials. Am J Obstet Gynecol. Jun 2004; 190(6):1520-6.

4. Abraham KA, Connolly G, Farrell J, Walshe JJ. The HELLP syndrome, a prospective study. Ren Fail 2001; 23:705-13.

5. Wolf JL. Liver disease in pregnancy. Med clin North AM1996; $80: 1167-87$

6. Weinstein L. Syndrome of hemolysis, elevated liver enzymes and low platelet count: a severe consequence of hypertension in pregnancy. Am JObstet and Gynecol 1982; 142:159-67.

7. Satpathy HK, Satpathy C, Donald F. Review Article on HELLP syndrome. JObstet Gynecol India 2009; 59:30-40.

8. Mackenna J, Dover NL, Brame RG. Preeclampsia associated with hemolysis, elevated liver enzymes and low platelet-an obstetric emergency? Obstet Gynecol 1983; 62:751-4.

9. Thiagarajah S, Bourgeoos FJ, Harben GM, Caudle MP. Thrombocytopenia in preeclampsia associated abnormalities and management principles. Am JObstet Gynecol 1984; 150-67. 
10. Sibai BM, Ramadan MK, Usta I, Salama M, Mercer BM, Friedman SA. Maternal morbidity and mortality in 442 pregnancies with HELLP syndrome. Am J Obstet Gynecol 1993; 169:1000-6.

11. Tranquilli AL, Giannubilo SR. The weight of total growth restriction in 437 hypertensive pregnancies. Arch Gynecol Obstet 2004; 270:214-16.

12. Prichard JA, Weissmann $R$, Ratnoff $O D$. Intravascular hemolysis, thrombocytopenia \& other hematologic abnormalities associated with severe toxemia of pregnancy. $N$ Engl JMed 1954; 250:89-98.

13. Sibai B, Kupferminc M. Preeclampsia. Lancet 2005; 365:78599.

14. Villar L, Say L, Gulmezoglu AM, Marialdi M, Lindheimer MD, Betran AP et al. Eclampsia and preeclampsia a worldwide health problem for 2000 years. In Critchly H, Maclean A, Poston L, Walker J, eds. Preeclampsia. London (UK): RCOG Press 2003: 189-207.
15. Dotsch J, Hohmann M, Kuhl PG. Neonatal morbidity and mortality associated with maternal hemolysis, elevated liver enzymes and low platelet syndrome. Eur J Pediatr 1997, 156:389-91.

16. Munday DN, Jones WR. Pregnancy complicated by antiphospholipid syndrome. Aust NZ J Obstet Gynecol 1993, $33: 255-8$

17. Kumru S, Simsek M, Gudretas B, sapmaz E. Comparison of maternal and perinatal outcomes of HELLP syndrome and severe preeclampsia. Perinatal J 2005; 13:9-14.

18. Liu CM, Chang SD, Chang PJ, Chao AS. Comparisons of Maternal and Perinatal outcomes in Taiwanese women with complete and partial HELLP syndrome and women with severe preeclampsia without HELLP. J Obstet Gynaecol Res 2006, 32(6): 550-8.

19. Yildinm G, Gungorduk K, Aslan H, Gul A, Bayraktar M, Ceylan Y. Perinatal and Maternal outcomes in pregnancy induced hypertension. J Turkish-German Gynecol Assoc 2011; 12:90-6. 